\title{
The impact of flood disasters on child education in Muzarabani District, Zimbabwe
}

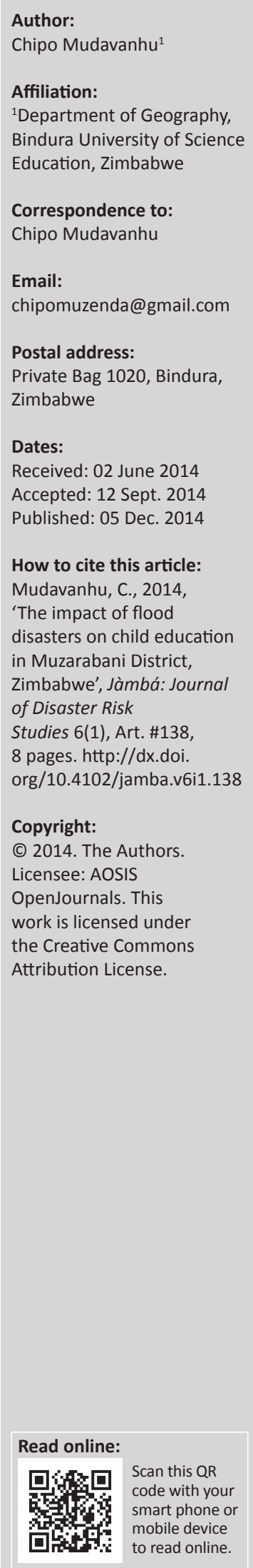

The increase in flood intensity and frequency poses a threat to community infrastructure and affects the total well-being of children in regard to: access to food, health, school attendance, access to clean water and sanitation, physical and social security. Using both qualitative and quantitative data, this article provided an overview of flood disasters and their potential effects on children's access to quality education in Zimbabwe. The purpose of the study was to analyse school children's specific vulnerabilities to flood disasters that need to be taken into account in policy development. Research indicated that floods cause loss of learning hours, loss of qualified personnel, outbreak of waterborne diseases, high absenteeism and low syllabus coverage leading to children's poor academic performance. Children noted a range of experiences, from food insecurity to being withdrawn from school and sometimes forced into early marriages. These challenges compromise children's rights and access to quality education. This article therefore recommended that a culture of safety be promoted through disaster education, development of good road networks and enforcement of building codes during construction of school infrastructure. Findings also supported the need for adaptation strategies to ensure that the risks specific to school children are addressed.

\section{Introduction}

Globally, disasters are increasing in frequency and intensity; they are often unforeseen, serious, cause threats and may bring injury and death in worst cases (Stanley \& Williams 2000). This is of major humanitarian concern and poses a threat to the achievement of Millennium Development Goals (UN Centre for Regional Development [UNCRD] 2009), especially the second goal of achieving universal primary education. Disasters can either be slow moving in their onset or sudden and unexpected (Peek 2008). Floods are amongst the most devastating natural disasters in the world and in Zimbabwe, in particular, where they have claimed lives and caused property damage over the past decade. The most vulnerable, yet understudied, group when disasters occur are school children. Flood effects to the socio-economic well-being of children have been well documented; yet, the impacts on children's access and right to quality education have received little attention (Masese et al. 2012). This has resulted in a lack of studies on the effects of floods on school children and infrastructure in Zimbabwe.

Based on the hypothetical view that frequently occurring disasters threaten communities, this study seeks to assess the effects of flood disasters on children's access and right to quality education in Zimbabwe. Using a case study approach, the article seeks to avail information on the challenges faced by school children in disaster-prone areas. The findings are a source of information in trying to address the challenges faced by children so that they can have access to quality education. Based on these research findings, it is hoped that the education system in disaster-prone areas of Zimbabwe will be enhanced in order for children to have equal access to quality education.

\section{Children and disasters}

Disasters threaten the lives, the rights and the needs of millions of children around the world. Children are more vulnerable because of their unique physiological, psychological and developmental attributes. Children's age has affected their vulnerability and shapes their ability to cope and survive during a disaster. The effects of these disasters can affect their future development potential. If parents' needs are met after a disaster we cannot assume that children's needs are also met; children may require different forms of physical, social, mental and emotional support than adults (Peek 2008). The loss of livelihood can lead to extreme poverty and may lead to school dropouts and malnutrition. Dropping out of school may lead to early marriages for the affected children, especially girls, and will result in them being trapped in a vicious cycle of poverty. This may cause slow development in the community making it more 


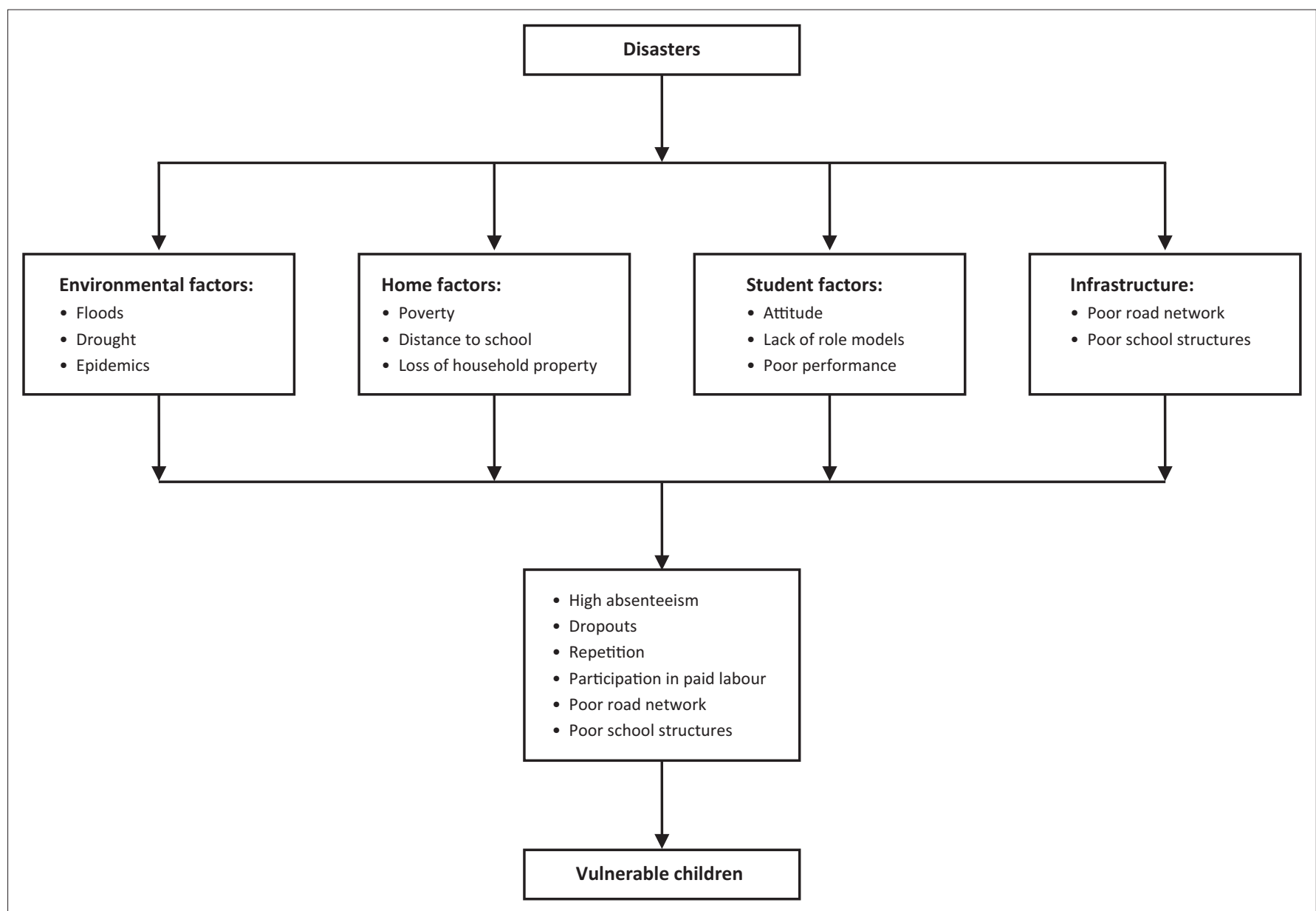

Source: Adapted from Okuom, H.A., Simatwa, E.M.W, Maureen, O.A. \& Wichenje, K.M., 2012, 'Assessment of factors that contribute to repetition and dropout of pupils in primary schools in flood prone areas of Nyando District, Kenya: An analytical study', Educational Research 3(2), 194

FIGURE 1: Factors that contribute to the vulnerability of children in flood disasters.

vulnerable to natural disasters. Children can be affected by disasters on their way to or from school, schools and homes can collapse and a loss of livelihoods can lead to food insecurity, amongst others. Disasters may sometimes result in missed school and delayed academic progress, missed social opportunities and increased exposure to various life stresses such as illness (Peek 2008). As summarised in Okuom et al.'s (2012) framework (Figure 1), disasters increase the vulnerability of children. The framework shows the factors that contribute to vulnerability, such as environmental, home, infrastructural and student factors. The effects of disasters on school facilities must not be seen only in terms of the need to prevent catastrophic damage that may destroy the buildings but also in terms of preserving the lives of children during disasters. The concept of school safety is not limited to preventing the collapse of school buildings in disasters, and ensuring the safety of teachers and students, but rather extends to disaster risk reduction (UNCRD 2009).

The specific vulnerability of children has been highlighted by recent catastrophic events. For example, in October 2005, an earthquake in Pakistan resulted in over 16000 children being killed when schools collapsed. In the Philippines, a landslide occurred on Leyte Island in February 2006, resulting in more than 200 school children being buried alive (Asian Disaster Preparedness Center [ADPC] 2007; Peek 2008). According to UNCRD (2009), an earthquake occurring in Gujarat in 2001 affected three million children. The potential impacts of these disasters are multiplied in developing societies, where the largest population demographic is children.

Schools play a vital role in every community (Shaw \& Kobayashi 2001; Stanley \& Williams 2000) and they need to be well secured and protected. The concept of school safety was given a major focus by the UN International Strategy on Disaster Reduction (UNISDR) during the 2006-2007 World Disaster Reduction Campaign, with the theme 'Disaster reduction begins at school'. This theme was chosen by UNISDR because it is in line with the Priority 3 of the Hyogo Framework for Action 2005-2015, which states that 'Use knowledge, innovation and education to build a culture of safety and resilience at all levels' (UNISDR 2007:9) and because schools are the best venues for forging durable collective values and therefore suitable for building a culture of prevention and disaster resilience (ADPC 2007). The campaign identified the reasons for which a school should be made safe, namely, (1) safety - as school buildings can save lives, (2) shelter - as schools be utilised 


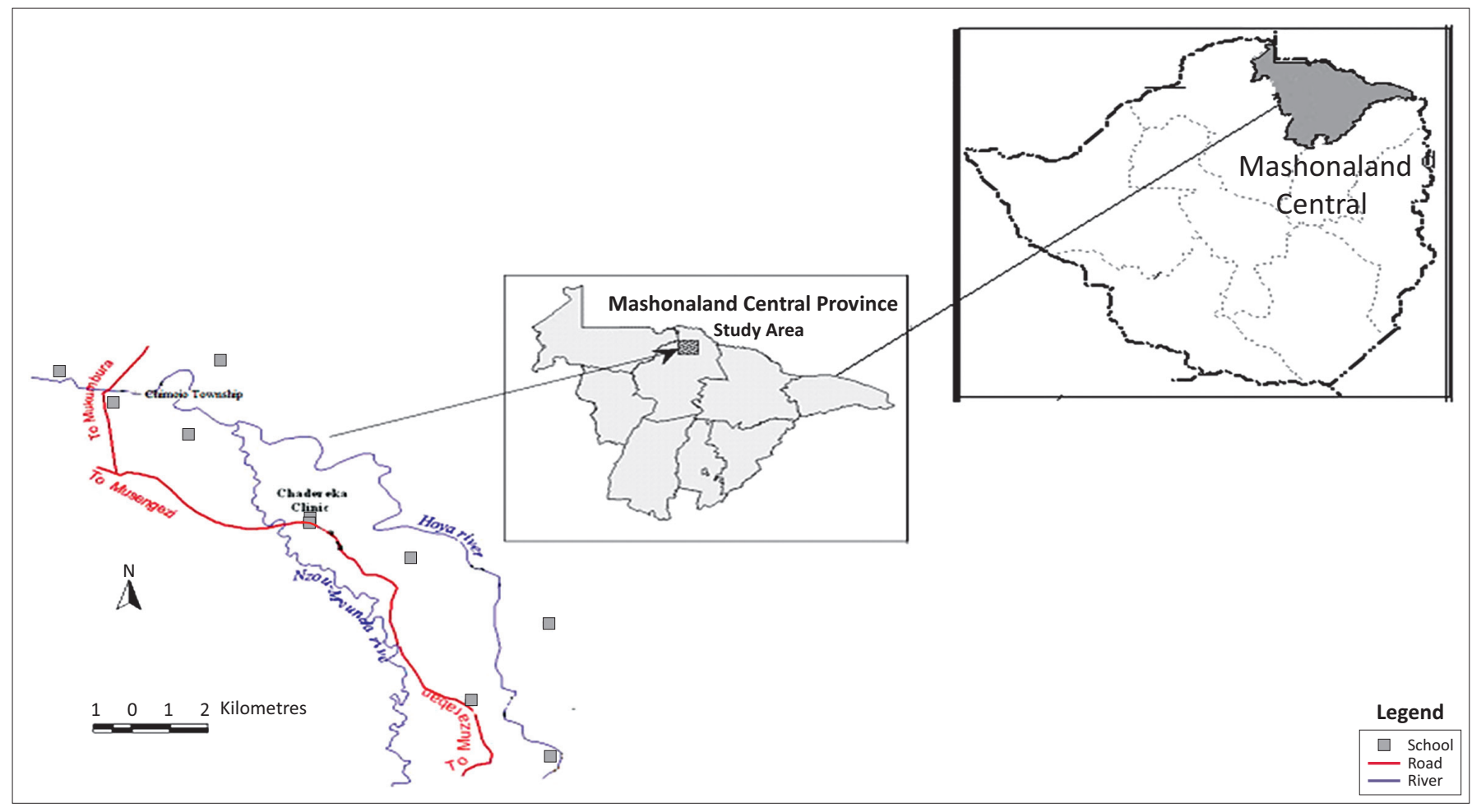

Source: Author's own construction

FIGURE 2: Map of the study area in Zimbabwe.

TABLE 1: School enrolment and sample size in the study area.

\begin{tabular}{lcccc}
\hline School & Year built & $\begin{array}{c}\text { First } \\
\text { enrolment }\end{array}$ & $\begin{array}{c}\text { Estimated } \\
\text { enrolment in 2012 }\end{array}$ & Sample size \\
\hline A & 1966 & 1041 & 700 & 70 \\
B & 1987 & 969 & 670 & 70 \\
C & 1986 & 560 & 650 & 65 \\
D & 2000 & 384 & 400 & 40 \\
E & 1986 & 169 & 345 & 35 \\
F & 2002 & 120 & 280 & 28 \\
G & 1994 & 546 & 650 & 65 \\
H & 2004 & 265 & 320 & 32 \\
I & 2004 & 313 & 360 & 40 \\
J & 2001 & 215 & 340 & 35 \\
\hline Total & - & - & 4715 & 480 \\
\hline
\end{tabular}

as shelters in an emergency period, (3) continuation of education - as education is disrupted in times of emergencies and (4) resource preservation - as schools are valuable local investment of a nation (ADPC 2007).

\section{Research method and design Study area}

Muzarabani District is located in the Mashonaland Central Province, in north-eastern Zimbabwe. It extends from $16^{\circ} 00^{\prime} \mathrm{S}, 30^{\circ} 45^{\prime} \mathrm{E}$ to $16^{\circ} 30^{\prime} \mathrm{S}, 31^{\circ} 20^{\prime} \mathrm{E}$ (Madamombe 2004). The district is found along the floodplains of the Zambezi River, with Lake Kariba upstream and Lake Cahora Bassa Dam downstream. The study was carried out in Ward 1 of the District, Chadereka, which is located at the confluence of Musengezi and Hoya Rivers about 400 m.a.s.l. and is $60 \mathrm{~km}$ from Muzarabani Business Centre, with about
6657 households (International Federation of Red Cross and Red Crescent Societies 2007) (Figure 2).

There are 10 schools in the ward: 9 primary and only 1 secondary school. All 10 are government schools and the community donated land for their construction. Table 1 shows a list of the schools (letters were used for security reasons) and the year the school was built. Only one school was constructed before the Zimbabwean independence of 1980 and the other nine were established after 1980. Most of the schools were built in areas that are not suitable for agriculture and some are in wetlands, such as the secondary school constructed in 2001, and others are very close to main rivers and streams.

Muzarabani in Zimbabwe's Shona language means 'flood plain', or an area that is frequently flooded, and Chadereka Ward 1 is the worst affected by natural disasters. The area suffers from disasters triggered by weather-related hazards, such as droughts and floods, and epidemics such as cholera and malaria. Although year-to-year droughts have been experienced, especially in 2000s, the present decade has seen floods of unprecedented magnitudes (Madamombe 2004). Perennial flooding is the leading cause of losses from natural hazards and is responsible for a greater number of damaging events in Muzarabani. The district is normally flooded from January to the end of the rainy season in March.

The floods are mainly caused by localised heavy seasonal rainfall and run-off, which often result in rivers overflowing. Cyclones, such as those in February 2000 and March 2003, are also responsible for flooding. The study area is most 
prone to flood disasters because it is at the confluence of Musengezi and Hoya Rivers. It is also affected by the backflow from Cahora Bassa Dam and inflows from the Zambezi River. Also, when the Kariba Dam water rises to a certain level, water is released to avoid dam failure. Most releases are done between January and March (rainy season), causing the discharge in the Zambezi River to increase substantially. Further downstream, the Cahora Bassa Dam levels continue to rise by inflows from tributaries to Lake Kariba and the Zambezi River, which then leads to backflow causing floods.

The population growth in the area increases the vulnerability of people, structures and goods and, worse still, people continue to construct in these flood-prone areas. Changes in environmental conditions (precipitation, changes in river courses and catchment areas) have worsened the situation. Apart from floods, Muzarabani is in Natural Region 4, which receives infrequent heavy rainfall subject to seasonal droughts. Droughts in the semi-arid region of Zimbabwe are becoming more frequent than ever before, threatening the Muzarabani community. The dependence on natural resources and rain-fed agriculture makes the area highly vulnerable to erratic rainfall. These climate extremes (floods and droughts) can also contribute to the outbreak of diseases such as cholera and malaria. Heavy rains tend to cause contamination of safe water contributing to the outbreak of cholera. Cross-border trading (Zimbabwe-Mozambique) because of food insecurity brings affected people and contaminated food into the area. Stagnant water after the floods is conducive for mosquitoes to breed. Muzarabani is also characterised by very high temperatures favoured by mosquitoes and malaria can create a crisis by imposing stress on the health system's ability to cope.

People are losing their lives as a result of these natural disasters. For example, the cyclone-induced floods in 2000 claimed the lives of 700 people, left more than 500000 people homeless and caused over $\$ 1$ billion of infrastructural damage in Zimbabwe and Mozambique (Wamukonya \& Rukato 2001). During the December 2007 floods, a total of 1000 households were affected, with 400 of them losing almost all of their belongings (International Federation of Red Cross and Red Crescent Societies 2007). Children end up not going to school during floods and this disrupts learning, resulting in very low pass rates.

\section{Procedure}

Besides the collection and analysis of documentary data, the research questions were addressed using a variety of methods for triangulation. The data were collected between September 2012 and March 2013 using questionnaires, focus group discussions and observations through transect walks. A questionnaire was administered to 480 school children ( 240 boys and 240 girls). Questions asked included: 'Have you ever witnessed a flood disaster?', 'What could you say about the floods?', 'How did you manage to survive?' and 'What are the problems that you faced during the disaster?'.
Although school children in Zimbabwean schools range from 5 to 18 years, the focus of this study was on children aged 9-18 years. The sample had the mean and modal age of 11 years in primary schools and the mean age of 16 years, with modal age of 17 years, in secondary schools. Stratified proportional sampling was used to come up with the number of children to be interviewed per school. A proportionate sample was considered in each stratum (schools). The researcher selected a sample of about $10 \%$ of the 4715 school children to reach the 480 who participated in the study (Table 1). This is supported by Ott (1993) who noted that the sample size should be at least $10 \%$ of the study population.

Five focus group discussions were held: one at every other school. Each focus group consisted of 10 pupils ( 5 boys and 5 girls) between 9 and 18 years; 9-13 years for primary and 13-18 years for secondary school. Consent for children to participate was sought from the school head teachers, the councillor and ward coordinator representing parents because the research was carried out in schools where parents often could not be reached. Consent was also sought from children themselves and parents (where possible) and their views and suggestions were listened to. In this study, children were seen as active subjects and not object of inquiry (Christensen \& James 2008). The researcher explained the inquiry to the children in their local language. The research procedures and aim were also explained clearly to the school children and teachers.

In all, 20 key informant interviews were conducted: with 5 school head teachers, a councillor, a ward coordinator, 10 teachers, a district education officer, a ward councillor and village health workers. Field observations and transect walks were undertaken with the ward councillor and coordinator and school head teachers to assess the nature and level of damage caused by floods. The researcher also visited some of the villages to assess the type of household dwellings and the nature of the roads used by children going to school.

\section{Results \\ Vulnerability of schools and school children to floods}

All the schools in the area were vulnerable to floods but the level of vulnerability varied. Three schools are located on uplands and were not considered physically vulnerable, but have pupils who cross rivers coming to the same school. These schools were never flooded but have been affected by storms. Of the rest, two schools were marginally vulnerable, whilst the other five were vulnerable to flood disasters.

Although some schools were never directly affected by floods, observations and consultations revealed that all schools $(100 \%)$ had poor infrastructure and were built by local people using local resources; no building codes were used, subjecting buildings to damage and collapse. Although the schools were built with bricks and cement, $80 \%$ of them had cracks on walls and $20 \%$ had roofs blown off. Apart from physical weaknesses of classroom structures, it was observed 
TABLE 2: Factors contributing to vulnerability of schools to flood disasters in Chadereka, as rated by teachers.

\begin{tabular}{|c|c|c|c|c|c|}
\hline \multirow[t]{2}{*}{ Factor } & \multicolumn{5}{|c|}{ Score } \\
\hline & SA & A & DA & SDA & Average $\%$ \\
\hline Terrain & 4 & 9 & 7 & 0 & 69 \\
\hline Poor structures & 3 & 12 & 5 & 0 & 75 \\
\hline Geographical location & 7 & 10 & 5 & 0 & 85 \\
\hline Climate change & 2 & 5 & 10 & 3 & 35 \\
\hline Lack of building codes for standard buildings & 7 & 13 & 0 & 0 & 100 \\
\hline
\end{tabular}

$n=20$.

SA, strongly agree; A, agree; DA, disagree; SDA, strongly disagree.

that all the schools are located along unmaintained roads, which are impassable during the rainy season because of the floods. The bridges connecting the communities have been destroyed by floods, making them difficult to access by road. This reduces communication amongst the schools in the area. There was also lack of furniture in the schools, with children being forced to sit on the floor. This disrupts learning and can affect the concentration of children. It was observed that most of the floors where they sit were also dusty, exposing children to multiple risks such as respiratory diseases.

Factors that contributed to the vulnerability of schools to flood disasters in the study area included terrain, poor structures, geographical location, climate change, lack of building standards, poverty and lack of resources (Table 2). School structures were built without building codes and were below standard, making them vulnerable to the compounding effects of floods. All the schools (100\%) had dilapidated facilities which were never maintained. Some had inadequate and temporary buildings. Two schools are located in wetlands and were normally flooded, whilst four are located at the confluence of Hoya and Musengezi Rivers making them more vulnerable to backflows. The other four schools are located close to the river on meandering channels, which means that any change in the river channel will affect the schools. Although the issue of climate change was mentioned as a contributing factor (35\%), $65 \%$ disagreed that it led to vulnerability of schools. However, $100 \%$ agreed that because there was no enforcement of building codes and standards in the area, most of the schools were below standard. Apart from building codes and standards being enforced, research also indicated that poverty and lack of resources to maintain school structures make them vulnerable to flood disasters.

Floods have also been blamed for loss of learning hours affecting the quality of education. In-depth interviews indicated that most teachers are failing to cover the school syllabus both at primary and secondary schools. This was said to affect the performance of the children in this area, as they will sit for the national examinations with other pupils whose learning was never interrupted. This is in line with Amer (2007) and Okuom et al.'s (2012) research findings that disasters result in teachers failing to complete the syllabus, leading to poor performance. Apart from losing contact hours at school, children highlighted that sometimes they do not attend school because rivers will be flooded, as some of the bridges were destroyed by Cyclone Elline in 2000, resulting in some communities being cut off:

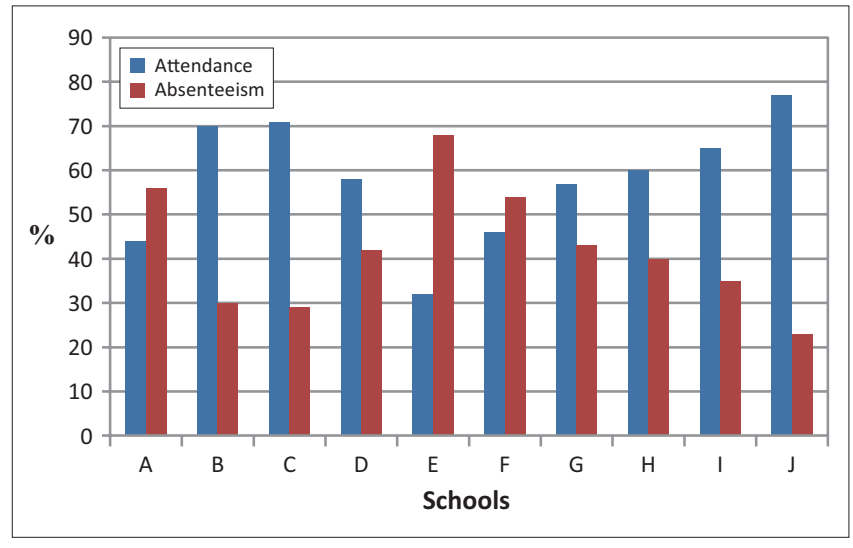

Source: Author's own construction

FIGURE 3: Rate of school absenteeism during the rainy season (January-March).

'During the rainy season we do not attend school because the rivers will be overflowing. There are no bridges on most of the rivers, some were destroyed and others were never constructed.' (13-year-old pupil, female, School B)

'It is difficult for us to cover the syllabus because during the rainy season most children do not come to school. We have to wait for them to so that they will not be disadvantaged.' (Head teacher, male, School $\mathrm{H}$ )

The highest rate of school absenteeism was recorded during the rainy season (January - March) (Figure 3); attendance during this period averaged 50\%, which implies that about half of the children do not attend school between January and March. Respondents highlighted that children in lower levels are normally compelled to stay at home a little longer because they cannot cross flooded rivers, which again affects their academic progress. Schools A, E and F were the most vulnerable to this form of absenteeism, with more than $50 \%$ of the children failing to attend school during the rainy season (Figure 3).

Children have also dropped out of school as a result of flood disasters. Of the 5730 children in Chadereka Ward aged 5-14 years, only about 4715 were being enrolled in school in 2012, implying that about 1015 children were not in school when they should have been. Reasons for low enrolment and dropouts are summarised in Table 3.

Focus group discussions with children and key informants indicated that there were many flood-related factors that contributed to school dropouts and absenteeism. Floods have contributed to poverty, food insecurity and damage to 
TABLE 3: Factors that contribute to school dropouts and absenteeism, as rated by key informants and children.

\begin{tabular}{|c|c|c|c|c|c|c|}
\hline \multirow[t]{2}{*}{ Factor } & \multirow[t]{2}{*}{ Respondent } & \multicolumn{5}{|c|}{ Score } \\
\hline & & SA & A & DA & SDA & Average $\%$ SA or A \\
\hline \multirow[t]{2}{*}{ Poor learning environment } & Key informants & 10 & 7 & 3 & 0 & 85 \\
\hline & Children & 120 & 280 & 80 & 0 & 83 \\
\hline \multirow[t]{2}{*}{ School too far } & Key informants & 7 & 5 & 8 & 0 & 60 \\
\hline & Children & 180 & 252 & 48 & 0 & 90 \\
\hline \multirow[t]{2}{*}{ Negative attitude to learning } & Key informants & 20 & 0 & 0 & 0 & 100 \\
\hline & Children & 0 & 70 & 410 & 0 & 15 \\
\hline \multirow[t]{2}{*}{ Parents cannot afford fees } & Key informants & 4 & 10 & 6 & 0 & 70 \\
\hline & Children & 60 & 390 & 30 & 0 & 94 \\
\hline \multirow[t]{2}{*}{ Early marriages } & Key informants & 3 & 13 & 3 & 1 & 80 \\
\hline & Children & 100 & 210 & 130 & 40 & 65 \\
\hline \multirow[t]{2}{*}{ Poverty forcing children to participate in paid labour } & Key informants & 9 & 5 & 4 & 2 & 70 \\
\hline & Children & 30 & 380 & 60 & 10 & 85 \\
\hline Food insecurity - cannot go to school hungry & Children & 35 & 45 & 375 & 25 & 17 \\
\hline
\end{tabular}

Key informants, $n=20$; Children, $n=480$.

$\mathrm{SA}$, strongly agree; $\mathrm{A}$, agree; $\mathrm{DA}$, disagree; SDA, strongly disagree.

TABLE 4: Teacher establishment status by 2012.

\begin{tabular}{|c|c|c|c|c|c|}
\hline School & Teacher in post & Qualified & Non-qualified (relief teachers) & School enrolment & Teacher-pupil ratio \\
\hline A & 17 & 4 & 13 & 700 & 47 \\
\hline B & 15 & 2 & 13 & 670 & 48 \\
\hline C & 15 & 2 & 13 & 650 & 46 \\
\hline D & 10 & 0 & 10 & 400 & 40 \\
\hline E & 10 & 1 & 9 & 345 & 38 \\
\hline $\mathrm{F}$ & 6 & 0 & 6 & 280 & 40 \\
\hline H & 6 & 0 & 6 & 320 & 53 \\
\hline I & 8 & 1 & 7 & 360 & 45 \\
\hline J & 10 & 3 & 7 & 340 & 34 \\
\hline Total & 111 & 15 & 96 & 4715 & 45 \\
\hline
\end{tabular}

school infrastructure, creating a poor learning environment. As a result of poverty, some children are being forced into early marriages. Others end up having a negative attitude to learning because of poor learning environments. Lack of financial resources has forced some parents to withdraw their children from school. Both key informants and children agreed that a poor learning environment is the highest contributing factor to school dropouts and absenteeism. Children highlighted that some of the classes are conducted outside and therefore it is impossible for them to be conducted during the rainy season. As a result, some children choose to be absent from school, whilst others end up dropping out.

Children always face challenges to access schools during the rainy season because of road damages and travelling across rivers. Rivers and streams are barriers to children who cross to get to their respective schools and these were also mentioned as a contributing factor to a poor learning environment. It was indicated that children who cross rivers arrive at school wet, making them uncomfortable to learn with others so they end up dropping out or staying at home.

There is also high teacher turnover. It was reported that that most of the teachers are relief members who never went through teacher education (Table 4). Qualified teachers were said to find it difficult to work in disaster-prone areas and more so in areas that are not accessible by road. Of all the teachers in posts, only the head teachers in some schools had undergone teacher education, whilst research also found that 3 of 10 head teachers also did not go through teacher education. This is also in line with Owiye (2005) and Okuom et al.'s (2012) findings that qualified teachers find it difficult to take up teaching posts in disaster-prone areas, leading to a shortage of qualified teachers and consequently affecting the quality of education. This has compromised the quality of education in the study area, leading to poor performance by pupils. The absence of qualified teachers has meant that schools receive new relief teachers every term and so there is no continuity in learning assessment. Children end up getting a new teacher every 3 months, compromising the quality of results as there is no sense of belonging by the respective teachers. Apart from lack of continuity resulting from high teacher turnover, most of the time schools run without a full teacher establishment as some teachers refuse to teach in the flood-prone areas.

High rates of malnutrition were also reported in the area. Floods have contributed to the loss of livelihoods in Muzarabani causing food shortages. Interviews revealed that the rate of absenteeism is high in families where there are food shortages and most of the children from these families do 
not perform well. This was also confirmed by Ayieko (2006), who revealed that because of food shortages after disasters, children normally help the family to get food, missing school in the process and eventually not performing well as a result of inconsistency in learning. Children highlighted that most of the time they miss school because they will be assisting parents to secure food for the family. This was said to contribute to high failure, dropout and absenteeism rates in the area.

Floods expose children to multiple health risks. Stagnant water exposes children to diseases such as cholera and malaria. Cholera was reported to be the most widespread illness causing loss of children's lives. The second most common disease is malaria, which was also reported to be claiming the lives of children in the study area. Interviews with health service officials indicated that they attend to cholera and malaria sicknesses more during the rainy season. This agrees with reports by the UN Children's Fund (UNICEF) (2009) and Ochola (2009) that malaria and cholera are a health menace in flood zones and are aggravated by low socio-economic status. It was also revealed that more children die of these epidemics than any other disease, although figures supporting this could not be availed.

Floods damage school infrastructure and property such as furniture, books, classrooms and toilets. It was reported that every time they experience floods, some classroom walls and toilets collapse with roof tops blown off. This poses a danger to children who spend most of the working hours in school. Children highlighted that because their classrooms have cracked walls they are always afraid and feel insecure. This is supported by Okuom et al.'s (2012) research findings that fear, insecurity and general high alert during floods reduced student's attention to learning, resulting to poor performance. The collapsed toilets forced some children to resort to bush toilets, leading to a high prevalence of cholera in schools as a result of water contamination. These unfavourable learning conditions have forced some children to drop out from school whilst others choose to stay away.

Most children reside in traditional dwellings with grassthatched roofs. Such houses are prone to damage during flooding. During the field visit, it was observed that $90 \%$ of the households had lost at least a hut. Ochola, Eitel and Olago (2010), in their research in Kenya, also noted that homes are as vulnerable as schools, which compounds the effects of floods on school children. Research revealed that some children whose houses were affected by floods dropped out of school, whilst others stayed at home trying to recover from the disaster impacts. This was said to increase the number of dropouts in the area and compromise the rights of children to education.

\section{Discussion}

\section{Response to flood disasters in Chadereka}

As a result of schools in Chadereka being vulnerable to flood disasters, the community has developed strategies to respond to their impacts in order to reduce vulnerability of children.
Some of the coping mechanisms include: school absenteeism, early marriages, engaging in paid labour, infrastructure development, selling livestock and taking children out of school. Research findings highlighted that most parents cannot afford school fees, $\$ 10$ per term, and they end up taking their children away. Head teachers reported that most of the dropouts are noticed after a flood disaster. Some parents were reported to force their young daughters into marriage as a survival strategy, whilst some children are being forced into paid child labour to assist parents in getting food for the family. Research revealed that most children who drop out of school do so to work as house maids or herd boys. Selling of livestock is also one of the common coping mechanisms in the area. Most households own livestock and these act as a safety net in case of a disaster. However, it was revealed that most households do not sell livestock to pay school fees but to buy food stuffs. Although these coping mechanisms seem to be viable for households, they are threatening children's lives. Children are becoming increasingly vulnerable in the Zambezi Valley.

Some positive response strategies do exist, often in the form of food aid from the government and non-governmental organisations such as Red Cross and Plan International, amongst others. Schools were also given free exercise and some textbooks from UNICEF Zimbabwe to ease the effects of disasters amongst children. To reduce the prevalence of malaria in the area, the region is fumigated on a yearly basis between September and December through the Ministry of Health and Child Care. With the help of community leaders and World Vision Zimbabwe, and using local resources, a foot bridge was also constructed to link the schools and the health centre with the community, to help children cross to schools in case of a flood. However, it appears that many of these response mechanisms are not well coordinated because of a lack of resources and poverty in the community.

Some of the community's response mechanisms, such as absenting and withdrawing children from school, sending children for paid labour and marrying children early, increase the vulnerability of children to flood disasters. It was observed that upon visiting the study area 6 months after a storm had blown off a roof top at one of the schools, it was discovered that nothing had been done to improve or renovate the buildings. A lack of resources was blamed for the delays in renovating the building. Besides lack of resources in the rural communities of Zimbabwe, disaster management is biased towards emergency response rather than mitigation. The tendency has been to wait and then start scurrying around for resources after a flood or cyclone has hit communities (Musarurwa \& Lunga 2012). Lack of resources to respond to emergencies is exposing children to increased risk of flood disasters.

\section{Conclusion}

Disasters result in disruptions in school children's learning, loss of contact hours, high rates of absenteeism and loss 
of qualified personnel affecting the quality of education in Zimbabwe. Floods contribute to the loss of human lives, livelihoods and property destruction, contributing to high levels of poverty. Disasters also undermine the education for all campaigns in most developing countries. However, although flood disasters are said to have major impacts on children's education and development, this research revealed that there is inadequate and, at times, inappropriate efforts to reduce the effects. Thus, the education system does not adequately cater for children in disaster-prone areas. They are treated the same as children in other areas and sit for the same national examinations, whilst the time lost as a result of disasters is not being compensated.

It has been observed that school children and infrastructure are vulnerable to flood disasters, compromising the children's rights to access to quality education, information, good sanitation, as well as their participation rights.

There is need to integrate disaster risk reduction into the education curriculum. Children need to be taught how to prepare, mitigate, prevent, respond to and recover from flood disasters. Both structural and non-structural measures need to be put in place to reduce the vulnerability of schools and children to flood disasters. Building codes and standards need to be enforced by policymakers to avoid the use of substandard buildings and building materials, as these threaten the lives of children and teachers. Before any construction of public buildings, there is need for land-use planning and zoning so that areas that are fragile will not be occupied. There is also need for road maintenance to schools and construction of bridges so that all the communities and schools will be accessible by road.

\section{Acknowledgements Competing interests}

The author declares that she has no financial or personal relationships that may have inappropriately influenced her in writing this article.

\section{References}

Amer, A.H., 2007, Responses to traumatized children, Palgrave Macmillan, Hampshire.

Asian Disaster Preparedness Center (ADPC), 2007, Child-focused disaster risk reduction Module 6: Community disaster risk reduction implementation, 16th Community-based disaster risk management course, Bangkok, 16-27 July.

Ayieko, P., 2006, Guidebook for planning education in emergencies and reconstruction, International Institute for Education and Planning, Paris.

Christensen, P. \& James, A., 2008, 'Researching children and childhood: Cultures of communication', in P. Christensen \& A. James (eds.), Research with children: Perspectives and practices, 2nd edn., pp. 1-8, Routledge, London.

International Federation of Red Cross and Red Crescent Societies, 2007, Zimbabwe Muzarabani floods, viewed 22 October 2011, from http://www.ifrc.org/docs/ appeals/07/MDRZM002a.pdf

Madamombe, E.K., 2004, Flood management practices - Selected flood-prone areas Zambezi Basin, Zimbabwe National Water Authority, Harare.

Masese, A., Opiyo R., Okayo, J. \& Ombui, N.M., 2012, 'Impact of floods on attainment of education for all (EFA) and vision 2030 in Nyando Basin', Kisumu County International Journal of Disaster Management and Risk Reduction 4(2), 19-31.

Musarurwa, C. \& Lunga, W., 2012, 'Climate change mitigation and adaptation: Threats and challenges to livelihoods in Zimbabwe', Asian Journal of Social Sciences \& Humanities 1(2), 25-32.

Ochola, S.O., 2009, Integrated flood hazard, vulnerability and risk assessment in Nyando River Catchment, Kenya: Options for landuse planning, Deutsche Nationalbibliothek, Heidelburge.

Ochola, S.O., Eitel, B. \& Olago, D.O., 2010, 'Vulnerability of schools to floods in Nyando River catchment, Kenya', Disasters 34(3), 732-754. http://dx.doi.org/10.1111/ j.1467-7717.2010.01167.

Okuom, H.A., Simatwa, E.M.W, Maureen, O.A. \& Wichenje, K.M., 2012, 'Assessment of factors that contribute to repetition and dropout of pupils in primary schools in flood prone areas of Nyando District, Kenya: An analytical study', Educationa Research 3(2), 190-201.

Ott, R.L., 1993, An introduction to statistical methods and data analysis, 4th edn. Duxbury Press, Belmont.

Owiye, D.O., 2005, 'Trend in and factors affecting wastage in primary education in Siaya District', MEd thesis, Department of in Educational Management and Foundations, Maseno University.

Peek, L., 2008, 'Children and disasters: Understanding vulnerability, developing capacities, and promoting resilience - An introduction', Children, Youth and Environments 18(1), 1-29.

Shaw, R. \& Kobayashi, M., 2001, Role of schools in creating earthquake-safer environment disaster management and educational facilities, UNCRD, Nagoya.

Stanley, P. \& Williams, S., 2000, After disaster: Responding to the psychological consequences of disasters for children and young people, New Zealand Council for Educational Research, Wellington.

UN Centre for Regional Development (UNCRD), 2009, Reducing vulnerability of school children to earthquakes: A project of school earthquake safety initiative (SESI), viewed 22 October 2011, from http://www.preventionweb.net/files/2951_ SESIOutcomeallfinal.pdf

UN Children's Fund (UNICEF), 2009, Floods devastate Agadez Region of northern Niger with lingering effects, viewed 22 October 2011, from http://www.unicef. org/infobycountry/niger_51221.html

UN Office for Disaster Risk Reduction, 2007, Hyogo Framework for Action 20052015. Building the resilience of nations and communities to disasters, ISDR, Geneva, viewed 22 October 2011, from http://www.unisdr.org/we/inform/ publications/1037

Wamukonya, N. \& Rukato, $\mathrm{H}, 2001$, Climate change implications for southern Africa: A gendered perspective, viewed 14 May 2013, from http://www.energia.org/ fileadmin/files/media/pubs/wamukonyarukato.pdf 